\title{
Reimagining Development in the UK? Findings from the UK Public Opinion Monitor
}

\author{
Johanna Lindstrom and Spencer Henson
}

\begin{abstract}
The UK Public Opinion Monitor (UKPOM) provides a unique opportunity to explore changes in attitudes of the UK public over time. This article presents findings from the UKPOM on how people in the UK have experienced the financial crisis and how, if at all, this has caused them to think differently about aid and development. We find that respondents had been affected by the economic crisis and were worried about the impact on their own finances and the UK economy. Although respondents had a feeling of interconnectedness with the world and were broadly supportive of aid in principle, these perspectives were often trumped by local and domestic priorities, particularly during such a period of financial turmoil, with support for aid spending in decline. We see some appetite for changing the way in which the world is governed, but the extent to which this encompasses aid reform is uncertain. Finally, we draw some conclusions for development policymakers and communicators.
\end{abstract}

\section{Introduction}

The Reimagining Development initiative comprised case studies from around the world. One of these was from the UK and investigated members of the UK public's experiences of the financial crisis and their attitudes to development and aid within this context. This case study used data from the UK Public Opinion Monitor (UKPOM). The UKPOM is a longitudinal panel of around 6,000 people from across the UK that is broadly representative of the demographic make-up of the population by gender, age, level of education and region. Members of the UKPOM receive an internet-based survey every six to eight weeks. For this article, we draw on analysis of results related to the Reimagining Development initiative from surveys conducted during the first year of operation, ${ }^{1}$ specifically attempting to answer the following questions:

1 To what extent has the UK public been affected by the financial and economic crisis and has the level of this impact changed throughout the year?

2 What are the experiences of the public with respect to interconnectedness between the $\mathrm{UK}$ and the rest of the world?
3 What are the attitudes of the public regarding aid and development and the UK's responsibilities within the context of the current economic environment and the UK budget deficit?

4 How do members of the public view the potential trade-offs between aid and other areas of government expenditure?

5 Can we say anything about whether there is appetite among the UK public to ways of reimagining development?

The UKPOM is a unique research instrument within the UK academic community. Although primarily aimed at understanding attitudes towards aid and development and what drives changes in these attitudes over time, the UKPOM also focuses on how people view aspects of life in the UK and beyond more generally. On the one hand, there is concern about biasing responses by only asking respondents about development and aid. On the other, our interest is in understanding how attitudes towards aid relate to broader social and political issues. ${ }^{2}$ 
As such, the UKPOM contributes to the body of knowledge of public attitudes to poverty, development and aid, including the tracking of public opinion on aid by DAC member countries and literature within development studies that compares and contrasts attitudes to aid across countries and the influence of a range of possible explanatory factors (OECD 2003; McDonnell et al. 2003; Chong and Gradstein 2006; Paxton and Knack 2008; Lumsdaine 1993). Also relevant is a body of literature, primarily within international relations and political science, which looks at attitude formation towards foreign policy and global justice (Beitz 1999; Holsti 1992; Goodin 1988; Jones 1999). A further literature, mainly from social psychology, explores understandings of the causes of poverty in developing countries and links to wider social attitudes, for example concepts of global justice (Harper et al. 1990; Carr et al. 1998; Carr and MacLachlan 1998; Hine and Montiel 1999; Bolitho et al. 2007; Panadero and Vazquez 2008). Combined, this literature presents a rather disparate body of knowledge that fails to throw significant light on key drivers of public attitudes to development assistance within donor countries (notable exceptions include Campbell et al. 2001; van Heerde and Hudson 2008; Noël and Thérien 2002). This is what the UKPOM aims to remedy.

\section{Impacts of the financial crisis}

Like many of the other places and spaces, our primary concern was to assess the extent to which members of the UKPOM had been affected by the financial crisis. We were also able to explore how this had changed throughout 2010. In June 2010, respondents were asked whether they had been affected by the economic crisis, with a small majority (52 per cent) indicating that the

financial situation of their household had become worse over the past 12 months. Looking forwards, 50 per cent of respondents expected the financial situation of their household to worsen in the coming year, while 37 per cent expected their household's finances to improve. In November 2010, respondents were again asked to reflect on their household's finances. This time, 56 per cent of respondents expected their financial situation to worsen over the next year or two, ${ }^{3}$ while only 16 per cent considered their household's finances would improve. This suggests considerable and worsening pessimism on the part of respondents with respect to their own financial situation in the context of the financial crisis and its aftermath, and the UK government's subsequent cuts in government spending to address the budget deficit.

\section{Global interconnectedness}

To link the findings from this case study to the more global focus of the Reimagining Development initiative, we endeavoured to assess the extent to which respondents felt their lives to be connected with the rest of the world. In March 2010, over 71 per cent of respondents considered the life of people in the UK to be dependent on what happens in other parts of the world. At the same time, the majority of respondents considered this dependency to be relatively weak. Thus, 53 per cent considered the life of people in the UK to be only 'fairly dependent' on what happens in other parts of the world. It is evident that many respondents had a rather nationalistic rather than a global focus on the world. Thus, when asked whether they considered themselves to be a global citizen, rather than a citizen of the UK, only 26 per cent agreed.

The global financial crisis had evidently served to highlight the level of economic interdependency between the UK and the rest of the world. Thus, over 94 per cent of respondents considered the state of the UK economy to be either 'very dependent' or 'fairly dependent' on what happens in other parts of the world. With the exception of the threat of terrorism, perceived levels of global interdependency were lower for other non-economic aspects of globalisation, in particular the level of crime and incidence of disease. While respondents evidently had a sense of being part of a 'bigger whole', the local evidently trumped the global.

\section{Support for aid}

This concept of the 'local trumping the global' was carried through in attitudes towards spending on aid to developing countries. In the context of efforts to reduce the budget deficit, respondents were asked how spending on various government services should change in the short term (June and November 2010) and in the next five to ten years (March 2011). ${ }^{4}$ Comparison of the results of the surveys shows appreciable differences in views on changes in government spending. Thus, 63 per cent of respondents in June 2010 and 71 per cent of respondents in November 2010 thought that spending on aid to developing countries should be cut in the context of efforts to address the budget deficit (Figure 1). 


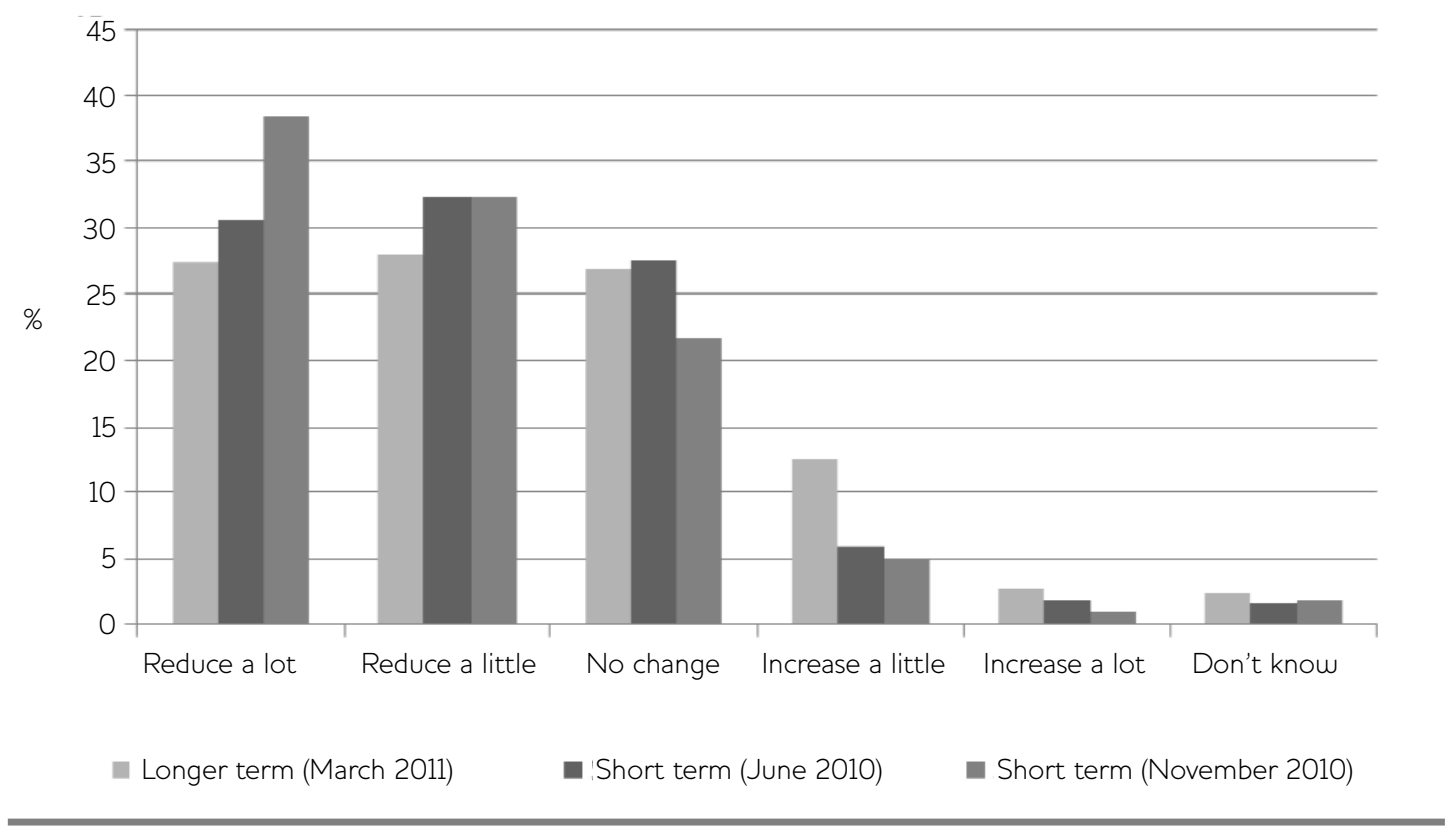

Taken with the results on impacts on household finances, it is clear that members of UKPOM see aid to developing countries as a prime target for cuts in times of austerity and when facing significant cut-backs in government expenditure. ${ }^{5}$ When we investigated attitudes towards aid more closely (June 2010), it was revealed how this 'charity begins at home' attitude was widespread, with a majority of respondents (64 per cent) considering tackling domestic poverty to be of greater priority for the UK government than tackling poverty abroad. ${ }^{6}$ There was also evidence of considerable scepticism about the effectiveness of aid, with a high level of agreement with statements such as, 'No matter how much aid is given to developing countries the situation never seems to get any better' (64 per cent) and 'Most aid to developing countries never gets to the poor' (60 per cent). Around 51 per cent of respondents agreed with the statement, 'Most aid given by the UK to developing countries is wasted', while relatively few (21 per cent) agreed that, 'By and large, the UK's aid to developing countries has been successful at reducing poverty'. Just over 45 per cent agreed that, 'Corruption in developing countries makes it pointless trying to help'.

Further results from the UKPOM suggest that these attitudes are influenced by the current economic climate. Thus, longer-term spending on aid was viewed more favourable. In the March 2011 survey, only 51 per cent of respondents considered spending on aid should be cut in the longer term. Further, while 38 per cent of respondents in November 2010 were of the view that spending on aid to developing countries should be reduced 'a lot' in the short term, only 27 per cent thought it should be reduced 'a lot' in the medium to long term. Over 15 per cent of respondents were of the view that aid spending should be increased in the longer term (Figure 1). These findings are supported by our investigation of attitudes to aid, the results of which suggest there is a recognised moral imperative to help the poor in developing countries, as indicated by the high level of agreement with statements such as, 'It is our obligation as human beings to help the poor in the world' (62 per cent); 'The wellbeing of others is just as important as my own wellbeing' (54 per cent) and 'The UK has a moral duty to help reduce poverty in developing countries' (51 per cent). Just over 51 per cent of respondents were of the view that 'The UK should be prepared to share at least some of its wealth with the poor in developing countries'.

Taken as a whole, these results suggest that, while there is an evidently strong sentiment that the UK has a moral commitment to help the 
global poor, this commitment is relatively 'shallow'. Thus, when the 'belt needs to be tightened' at home, aid spending is one of the first target areas. The contrast to the commitment of the current government, and indeed all of the major political parties in the recent general election, to at least maintain spending on aid to developing countries is stark. Econometric analysis of the survey results suggested that perceptions of a moral duty to help the poor was the single most important determinant of attitudes towards cutting or maintaining aid spending. At the same time, evidently, perceptions that aid does not work, are widespread. Indeed, the econometric analysis suggests that perceptions of corruption and whether aid to date has been effective in reducing poverty, for example, are important (although secondary to moral commitment) determinants of attitudes towards UK government spending on aid. This suggests that, in times of austerity, attitudes towards aid are driven by basic values.

\section{Reimagining development more broadly in the UK?}

It seems that the economic crisis has created a somewhat hostile environment for development in the UK, at least from the perspective of spending on aid. However, the Reimagining Development initiative is about more than increasing aid. Thus, can we see any appetite for reimagining development from a wider perspective within the UK population?

In the first UKPOM survey (March 2010), almost half of respondents were of the view that we are now at a time when there is a need to rethink global governance. Thus, 48 per cent agreed with the statement, 'Some people have argued that the global financial crisis, alongside longer-term issues such as climate change, presents a time to rethink how the world is governed'.

Respondents were presented with a specific proposal - the so-called 'Tobin' or 'Robin Hood' tax on global financial transactions as a means to examine attitudes towards specific proposals for change. Around 43 per cent of respondents indicated that they had heard of this idea previously, while 49 per cent indicated that they would support such a move if it was to be proposed internationally. At the same time, however, 41 per cent of respondents did not know whether they would support the Tobin tax, suggesting a considerable level thought the proceeds should be used to reduce the debt of high-income countries, such as the UK. Financing aid to poor countries was supported by 40 per cent of respondents, only marginally less than the proportion supporting the use of the proceeds to fund insurance for a possible future banking crisis or to help offset the impacts of climate change.

\section{Conclusions}

So what do these initial results from the UKPOM mean for reimagining development? On the one hand, they are quite heartening; even in times of austerity, there are prevailing views that we have a moral obligation to help the poor in the world. On the other, when it comes to support for spending on aid - putting our money where our mouth is - such values appear to be overridden by domestic priorities and scepticism over whether aid actually works. In 'hard times' embedded beliefs, and also often quite wild stereotypes, of wastage and corruption come 'bubbling to the surface'.

These results have important implications for development communications. Certainly we might be able to attack prevailing attitudes that much aid is wasted and that efforts to reduce global poverty are doomed to failure in the shadow of corruption, for example gathering evidence that aid does indeed work, and packaging this into messages that people can attend to and that accord with their existing frames of reference. However, more fundamental values with respect to moral duty appear to be a bigger driver of support for continuing aid spending. Values are more difficult to change, requiring longer-term and concerted efforts to raise awareness of global issues and re-orientate value systems towards personal responsibilities. At the same time, this perhaps accords well with the current government's focus on the 'big society'?

Perhaps it is time to be more open and honest about aid? As Riddell (2007) argues, donor communication efforts can take three approaches: (1) trying to convince the public that some aid does work; (2) trying to convince the public that steps are being taken to enhance the impact of aid; and (3) taking a more long-term strategy to 'nurture, extend and deepen support for aid', acknowledging failure as well as successes, and being more open about what aid 
can achieve and what it cannot. To date, most donor communication strategies have focused on the first two options, arguably because of fears that being honest about failure will undermine what support for aid there is. Certainly there is a risk of this, especially when the frame of reference points towards scepticism. But in turn, this also raises questions over continuing to 'preach to the converted'? Perhaps what is needed is a more considered approach to development communication? Such a strategy could include being clear and upfront about what development assistance can achieve and what it cannot, and about the difficulties faced in working in developing countries. Development is a complex business and we should not give the impression that aid is capable of solving

\section{Notes}

1 In this article, results from surveys in March, June and November 2010 and March 2011 are presented here. The analysis is mostly based on univariate statistics. However, some preliminary econometric analysis using a probit model has been undertaken, specifically on attitudes towards UK aid to developing countries.

2 For more information about the UKPOM, see www.ukpublicmonitor.org, including full results from all surveys and further information about the methods employed.

3 These questions were slightly different in that the one from June 2010 referred to the next 12 months, whereas the question in November 2010 referred to the next 1-2 years.

4 Respondents were asked how spending on a range of government services should be changed on a fine-point scale from: 'reduce a

\section{References}

Beitz, G.R. (1999) 'International Liberalism and Distributive Justice: A Survey of Recent Thought', World Politics 51: 269-96

Bolitho, F.H.; Carr, S.C. and Fletcher, R.B. (2007) 'Public Thinking About Poverty: Why it Matters and How to Measure it', International Journal of Nonprofit and Voluntary Sector Marketing 12: $13-22$

Campbell, D.; Carr, S.C. and MacLachlan, M. (2001) 'Attributing "Third World Poverty" in Australia and Malawi: A Case of Donor Bias?', Journal of Applied Social Psychology 31.2: 409-30

Carr, S.C. and MacLachlan, M. (1998) 'Actors, Observers and Attributions for Third World everything (see Henson et al. 2010 for a longer discussion).

Finally, what about the bigger picture? Does the UK public see these as times when we need to rethink global governance, and in particular development? If so, what changes need to happen? On the former of these issues, the survey results do give some credence. Among significant numbers of our respondents, there was a recognition that 'things need to change', at least in principle. On the latter, we have yet to gather sufficient data. As the UK Public Opinion Monitor proceeds, we aim to explore attitudes to development and aid in more depth, and to look more closely at how these change and why. Watch this space!

\section{lot' (1) to 'increase a lot' (5). Note that} respondents were presented with information on the magnitude of spending in each area in 2009, and thus saw how small a proportion of government spending these areas constituted (e.g. $£ 80$ per person was spent on aid to developing countries) in comparison with areas such as health, which constitutes a large proportion of government spending ( $£ 1,808$ spent per person).

5 This was also confirmed by questions about the value people placed on aid in relation to other government services and as a factor determining their voting behaviour.

6 Respondents were presented with a range of attitudinal statements and asked to indicate the degree to which they agreed with each on a five-point scale from: 'strongly disagree' (1) to 'strongly agree' (5).

Poverty: Contrasting Perspectives from Malawi and Australia', Journal of Social Psychology 138.2: 189-202

Carr, S.C.; Taef, H.; de Ribeiro, R. and MacLachlan, M. (1998) 'Attributions for "Third World" Poverty. Contextual Factors in Australia and Brazil', Psychology and Developing Societies 10.2: 103-14

Chong, A. and Gradstein, M. (2006) Who's Afraid of Foreign Aid? The Donors' Perspective, Research Department Working Paper Series 546, Washington DC: Inter-American Development Bank

Goodin, Robert E. (1988) 'What is So Special about our Fellow Country Men?’, Ethics 98: 663-86 
Harper, D.J.; Wagstaff, G.F.; Newton, J.T. and Harrison, K.R. (1990) 'Lay Causal Perceptions of Third World Poverty and the Just World Theory', Social Behaviour and Psychology 18.2: 235-8

Henson, S.; Lindstrom, J. and Haddad, L. (2010) Public Perceptions of International Development Support for Aid in the UK: Results of a Qualitative Enquiry, IDS Working Paper 353, Brighton: IDS

Hine, D.W. and Montiel, C.J. (1999) 'Poverty in Developing Nations: A Cross-Cultural Attributional Analysis', European Journal of Social Psychology 29.7: 943-59

Holsti, O.R. (1992) 'Public Opinion and Foreign Policy: Challenges to the Almond-Lippmann Consensus', International Studies Quarterly 36: $439-66$

Jones, C. (1999) Global Justice: Defending Cosmopolitanism, Oxford: Oxford University Press Lumsdaine, D.H. (1993) Moral Vision in International Politics: The Foreign Aid Regime, 1949-1989, Princeton: Princeton University Press

McDonnell, I.; Lecomte, H.-B. and Wegimount, L. (2003) Public Opinion Research, Global Education and Development Cooperation Reform: In Search of a Virtuous Circle, Paris: Organisation for Economic Cooperation and Development (OECD)
Noël, A. and Thérien, J-P. (2002) 'Public Opinion and Global Justice', Comparative Political Studies 35.6: $627-52$

OECD (2003) Public Opinion and the Fight Against Poverty, Paris: Organisation for Economic Cooperation and Development

Panadero, S. and Vazquez, J.J. (2008) 'Perceived Causes of Poverty in Developing Nations: Causes of Third World Poverty Questionnaire in Spanish-Speaking Samples', Social Behaviour and Personality 36.4: 571-6

Paxton, P. and Knack, S. (2008) Individual and Country-Level Factors Affecting Support for Foreign Aid, Policy Research Working Paper Series WPS 4714, Washington DC: World Bank

Riddell, R. (2007) Does Foreign Aid Really Work?, Oxford: Oxford University Press

van Heerde, J. and Hudson, D. (2008) 'Public Attitudes Towards Development in the UK: Self-interest, Moral Judgements and the Media', paper presented at the annual meeting of the ISA's 49th Annual Convention, Bridging Multiple Divides, Hilton, San Francisco, www.allacademic.com/meta/ p_mla_apa_research_citation/2/5/3/0/5/ p253058_index.html (accessed 17 May 2011) 